\title{
The central mechanisms of secretin in regulating multiple behaviors
}

\section{Li Zhang and Billy K. C. Chow*}

School of Biological Sciences, University of Hong Kong, Hong Kong, China

\section{Edited by:}

Jae Young Seong, Korea University, South Korea

\section{Reviewed by:}

David Vaudry, INSERM, France

Adalberto Merighi, University of Turin Italy

\section{*Correspondence:}

Billy K. C. Chow, School of Biological Sciences, University of Hong Kong,

Kardoorie Biological Science Building,

Pokfulam Road 4N-12, Sai Ying Pun,

Hong Kong, China

e-mail: bkcc@hku.hk
Secretin (SCT) was firstly discovered as a gut peptide hormone in stimulating pancreatic secretion, while its novel neuropeptide role has drawn substantial research interests in recent years. SCT and its receptor (SCTR) are widely expressed in different brain regions, where they exert multiple cellular functions including neurotransmission, gene expression regulation, neurogenesis, and neural protection. As all these neural functions ultimately can affect behaviors, it is hypothesized that SCT controls multiple behavioral paradigms. Current findings support this hypothesis as SCT-SCTR axis participates in modulating social interaction, spatial learning, water and food intake, motor coordination, and motor learning behaviors. This mini-review focuses on various aspects of SCT and SCTR in hippocampus, hypothalamus, and cerebellum including distribution profiles, cellular functions, and behavioral phenotypes to elucidate the link between cellular mechanisms and behavioral control.

Keywords: secretin, social behavioral, water and food intake, motor coordination and learning, neural transmission, neural development, knockout mice

\section{INTRODUCTION}

For the survival of animals, it is critical to control complex behaviors in a timely and precise manner via regulatory pathways including sensory inputs, integration in the central nervous system (CNS), and coordinated motor outputs to peripheral muscles. Within these modulatory processes, various neuroendocrine factors exert their roles. Classical neurohormones such as those from the hypothalamus-pituitary system (i.e., sex hormones, growth hormone, etc.) have been comprehensively studied regarding their behavioral effects. Moreover, a recently discovered group of "neuropeptides" began to show plausible neurophysiological functions. Among those, secretin (SCT) has been repeatedly reported by independent groups to modulate behavioral paradigms.

Secretin was initially considered to be a duodenum-derived chemical factor in stimulating pancreatic secretion (1). However, several studies in 1980s suggested its presence in the brain (24). The introduction of immunohistochemical (IHC) and in situ hybridization (ISH) staining discovered SCT and its receptor (SCTR) in multiple brain sites as summarized in Table 1. In adult brains, SCT and SCTR were: (1) expressed in hindlimb area of cerebral motor cortex and prominently distributed in hippocampus; (2) abundantly found in thalamus and hypothalamus; (3) not present in midbrains except for embryos; and (4) widely distributed in hindbrain regions including cerebellum and medulla oblongata. During embryonic development, transcripts and proteins of SCT and transcripts of SCTR were found in cerebellar primordium, tegmentum, and mesenchyme flexure as early as embryonic day $10.5(5,6)$. As these SCT- or SCTR-expressing neurons control unique behaviors (i.e., hippocampus: learning and memory; hypothalamus: sex, drinking, and feeding; cerebellum: motor coordination and motor learning), it was postulated that SCT had a role in multiple behaviors. The following part will describe past studies regarding the role of SCT in behavioral modulations.

\section{SCT IN HIPPOCAMPUS CONTROLS SOCIAL BEHAVIOR AND SPATIAL LEARNING}

Hippocampus has been well-known to be responsible for social behavior, memory, and spatial learning, all of which are dependent on neurogenesis and synaptic plasticity (21-23). Hippocampal neurons were found to express significant SCT and SCTR as described in Table 1. Functional evidences including activated adenylate cyclase (24) and increased secretion of neurotransmitter glutamate and gamma-aminobutyric acid (GABA) by SCT (25) further supported SCT in hippocampal regulated behaviors.

One clinical trial reported that intravenous (IV) SCT injection improved eye contact, alertness, and expressive language ability on children with autistic spectrum disorders (ASD) (26). Replicated studies, however, had no significant effects (27) or only marginal improvements on some individuals (28-30), thereby rejecting SCT as an effective treatment against ASD (31). Although clinical studies did not get satisfactory results, animal experiments did reveal the role of SCT in social behaviors. A complete behavioral phenotyping in SCTR knockout (KO) mice reported impaired social interaction as shown by higher dominance percentage in a tube test and lower recognition ratio in a partition test (9). Such behavioral impairments were attributed to neuroanatomical and electrophysiological abnormalities: SCTR KO mice had fewer dendritic spines on CA1 pyramidal cells, in addition to impaired long-term potentiation (LTP) induction and maintenance (9). This synaptic plasticity dysfunction reoccurred in SCT KO mice which, however, had normal dendritic morphology (8). In behavioral studies, SCT $\mathrm{KO}$ mice had impaired spatial learning in the water maze task as they spent longer time to find the relocated hidden platform (32). 
Table 1 | Brain distributions of SCT and SCTR.

\begin{tabular}{|c|c|c|c|c|}
\hline Anatomical division & Subdivision & Neuron/neuron group & Expression profile & Reference \\
\hline \multirow[t]{3}{*}{ Telencephalon } & Cerebral cortex & Pyramidal cell & SCT peptide ${ }^{a}$ & (7) \\
\hline & Hippocampus & DG, hilus, molecular layer & SCT gene ${ }^{b}$ & (8) \\
\hline & & CA1 & SCTR gene ${ }^{b}$ & (9) \\
\hline \multirow[t]{4}{*}{ Diencephalon } & Thalamus & Laterodorsal thalamic nucleus & SCTR gene & $(10)$ \\
\hline & Hypothalamus & SON, PVN, Arc & SCT + SCTR gene + peptide & $(11-14)$ \\
\hline & Posterior pituitary & Herring bodies in pars nervosa & SCT + SCTR peptide & $(13)$ \\
\hline & CVO & SFO, OVLT & SCT + SCTR gene + peptide & $(15)$ \\
\hline Mesencephalon & Midbrain & & $\mathrm{NSE}^{\mathrm{C}}$ & $(16)$ \\
\hline \multirow[t]{3}{*}{ Rhombencephalon } & Cerebellum & Purkinje neuron, DCN & SCT gene + peptide & $(17-20)$ \\
\hline & & Purkinje neuron, basket cell & SCTR gene & $(17,19)$ \\
\hline & Medulla oblongata & NTS & SCTR gene & $(10)$ \\
\hline
\end{tabular}

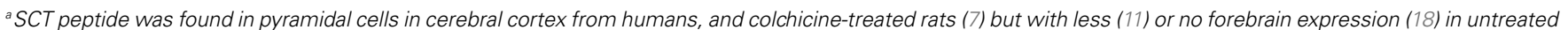
rats.

${ }^{b}$ SCT and SCTR gene expression was detected by staining the lacZ reporter.

' SCT and SCTR expression was found in embryonic mesencephalic neurons until birth $(5,6)$ but not in adults (16).

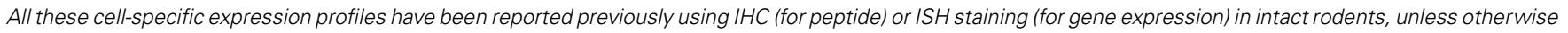
specified.

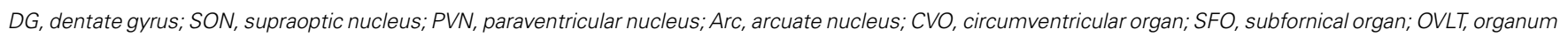
vasculosum of lamina terminalis; NSE, no significant expression; DCN, deep cerebellar nucleus; NTS, nucleus tractus solitarius.

In concurrent histological and electrophysiological examinations, higher apoptosis of neural progenitor cells in DG during postnatal development occurred, along with impaired LTP (32). In summary, SCT was involved in hippocampal neurogenesis and neural transmission including synaptic plasticity, all of which contributed to social behavioral and spatial learning as illustrated in Figure 1B.

\section{HYPOTHALAMIC SCT STIMULATES WATER DRINIKING}

In the classical model for water homeostasis, vasopressin (VP) from posterior pituitary functions as an antidiuretic factor to induce renal water reabsorption while liver-originated angiotensin II (ANGII) has central effects stimulating VP release and water intake in hypothalamic neurons. Our research group for the first time reported polydipsia and polyuria in SCTR KO mice under both normal (33) and hyperosmolality conditions (34). Followup studies revealed that SCT was released from posterior pituitary following hyperosmolality stress to stimulate VP secretion (13). Therefore, the interruption of SCT-SCTR axis decreased VP secretion and led to lower renal water reabsorption, which further induced polyuria and stimulated water drinking as a consequence. We also measured central effects of SCT in drinking behaviors: intracerebroventricular (ICV) injection of SCT increased water intake in both wild type (WT) and SCT KO mice but not in SCTR $\mathrm{KO}$ ones (15). This potentiation, however, did not occur when SCT is peripherally injected (35). More importantly, ICV ANGII injection induced dipsogenic effects in WT mice but not in SCT KO or SCTR KO ones (15). This clearly suggested that ANGII exerted water intake control via SCT-SCTR-dependent pathways. Evidences supporting this model came from the co-localization of SCT and ANGII receptor type 1 (ATlaR) in hypothalamic PVN, along with the induction of Sct gene expression in SFO, OVLT, and PVN following centrally (15) but not peripherally injected ANGII (35). This sequential induction of Sct gene expression plus a higher Fos-immunoreactivity in SFO after ICV SCT injection (35) suggested that SCT firstly activated SFO, which then relayed the signal via OVLT to PVN to evoke drinking behaviors. In a word, SCT worked in conjunction with ANGII to stimulate water intake.

There were unsolved questions in the aforementioned model: ICV ANGII still induced water intake in SCT KO and SCTR $\mathrm{KO}$ mice, although at dramatically reduced levels compared to WT controls (15). This phenotype suggested that some SCTindependent pathways must exist although SCT-mediated ANGII regulation was more potent in terms of water intake control. This riddle has partially been elucidated in our recent study, which proposed a receptor heteromer between SCTR and ATlaR (34). As illustrated in Figure 1C, this receptor complex endowed strong synergistic effects to SCT and ANGII as low concentration of both peptides (10 ng ANGII, $50 \mathrm{ng}$ SCT) had comparable dipsogenic phenotypes as those produced by 10 -fold concentration of each peptide alone (34). In addition, we were able to totally abolish hyperosmolality-induced water intake via ICV injection of AT1aR transmembrane peptide-1 (ATM-1), which inhibited SCTR/AT1aR heteromer formation only but not SCTR/SCTR or ATlaR/AT1aR homomer on the cell surface (34). This working model indicated the potential in vivo role of SCTR/AT1aR heteromer in regulating water drinking behaviors as both receptors were co-expressed in the same hypothalamic neurons (15).

\section{SCT SUPPRESSES FOOD INTAKE via THE MELANOCORTIN SYSTEM}

Previous studies reported appetite control by SCT but were somehow inconsistent. Peripheral SCT injection led to depressed food intake in both normal feeding (36) and fasted animals (37). Rat feeding pattern, however, was unaffected by intraperitoneally (IP)-injected SCT (38). Our research group recently reported a 


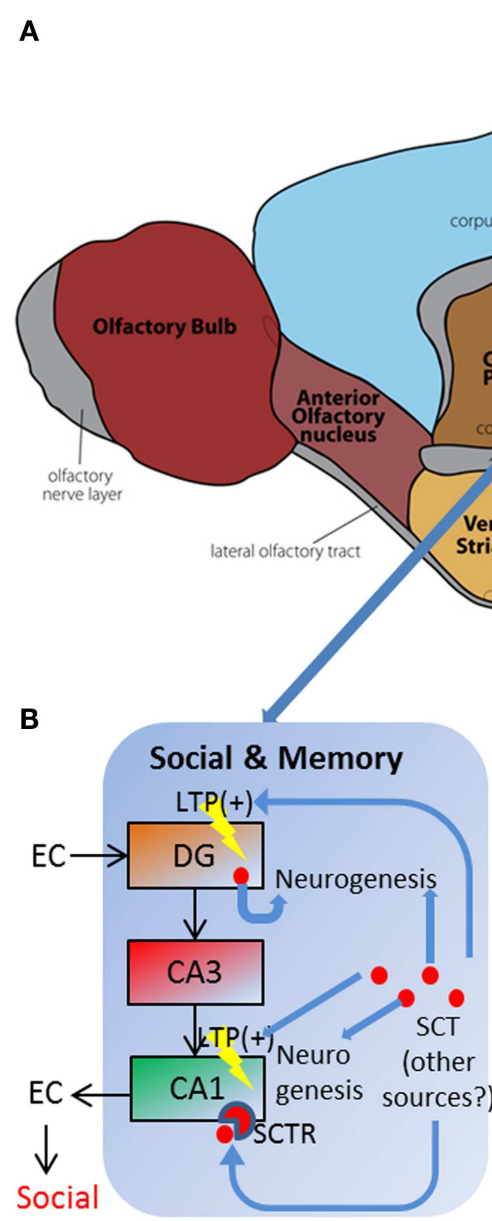

Spatial learning
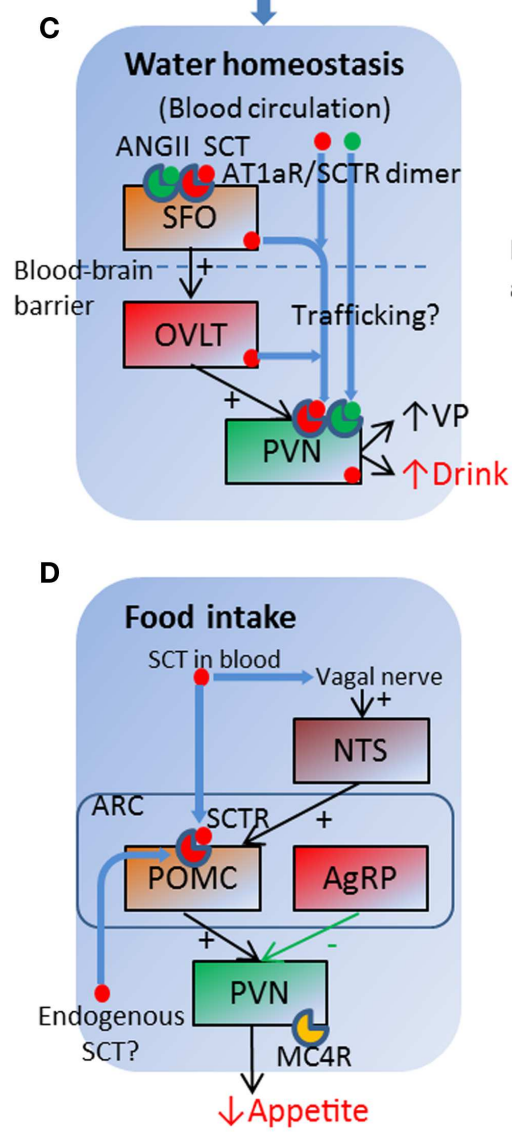

Figure legend

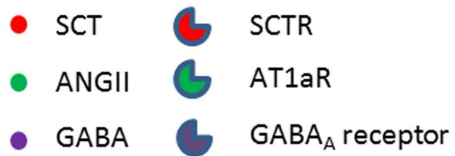

FIGURE 1 | Schematic illustration of SCT as a pleiotropic neuropeptide in regulating behavioral paradigms. (A) Functional regions of a mouse brain, in which three sites with prominent SCT and SCTR expression are further illustrated in (B-E). (B) SCT can modulate social and memory via both LTP control and neurogenesis in hippocampal DG and CA1 regions. EC, entorhinal cortex. (C) SCT works in conjunction with ANGIl to exert a synergetic effect on hypothalamic SFO, which then relays the signal to PVN for the induction of water intake behavior. (D) Both vagal nerve and Arc neurons are responsive to SCT and further inhibit food intake via the activation of the melanocortin system. (E) SCT can induce presynaptic GABA release, and potentiate LTP in PF-PC synapse. BC, basket cell; PC, Purkinje cell; PF, parallel fiber. (A) is adapted from an illustration of the Gene Expression Nervous System Atlas (GENSAT) Project, NINDS Contracts N01NS02331 \& HHSN271200723701C to The Rockefeller University (New York, NY) with permission. 
suppression of food intake in fasted mice by either IP or ICV SCT administration (14). This effect was determined to be SCTRspecific as SCTR KO mice did not exhibit such anorectic effects (14). Further studies revealed that both central and peripheral pathways existed under these feeding pattern changes. In hypothalamus, ICV injection of melanocortin-4 receptor (MC4R) antagonist SHU9119 reduced IP- or ICV-induced food intake suppression in WT and SCT KO mice (14). This information plus the SCT-stimulated expression of Mc4r, Trh, and Pomc gene (14), all of which are factors in melanocortin system for appetite control, clearly suggested that SCT works via the activation of melanocortin system to inhibit food intake (Figure 1D). SCT was believed to be endogenously released from hypothalamic neurons (12), although in vivo evidence was still lacked. In addition to this central mechanism, circulated SCT functioned via vagal afferent nerves as either surgical vagotomy or neurotoxin capsaicin treatment eliminated food intake suppression caused by IP- but not ICV-injected SCT (39). This is consistent with previous studies showing that peripheral SCT is able to activate vagal afferent and area postrema (AP) neurons (40). SCT induced Fos-immunoreactivity in NTS, AP, and dorsal vagal complex (DVC) after IP injection in intact mice but not in vagotomized or capsaicin-treated ones (39). Brainstem activation then stimulated POMC neurons in Arc, which is Fos-positive after IP SCT infusion (14). However, this effect was abolished when animals are vagotomized or capsaicin-treated (39). In summary, SCT either locally activated the melanocortin system in an auto-/paracrine manner or worked via vagal nerve to suppress food intake (see Figure 1D for a simplified working model).

Besides direct regulation on food intake, SCT may also participate in the regulatory network and cross-talk with other hormones to control the appetite. One possible candidate leptin, was synthesized from adipocytes and inhibited Arc neurons expressing neuropeptide Y (NPY) and agouti-related peptide (AgRP) whilst stimulated $\alpha$-melanocyte-stimulating hormone $(\alpha-\mathrm{MSH})$, thereby suppressing food intake. The IV infusion of SCT increased plasma leptin levels (41), thereby inhibiting feeding behavior. It was further noticed that ICV-leptin elevated SCT expression in ventromedial hypothalamus (42). So SCT and leptin may work synergistically to exert the anorexic effect, as those for SCT and ANGII in water intake control. Such cross-talk may be further broadened, for example, cholecystokinin (CCK) can also synergistically interact with SCT at the vagal afferent nerve (43). More gastrointestinal hormones including glucagon-like peptide1 (GLP-1), ghrelin, and amylin also activated certain SFO neurons (44). Thus SCT may collaborate with other gut peptides to form an integrated network modulating feeding behavior.

\section{SCT REGULATES MOTOR COORDINATION AND MOTOR LEARNING BEHAVIOR via THE FACILITATION OF PURKINJE NEURON INHIBITORY TRANSMISSION}

Motor effects of SCT were initiated by Charlton's group, who discovered a lowered open-field activity and novel object approach after ICV injection of SCT (45), and a later one in which SCT was found to increase the latency of withdrawal jumping response (46). In SCTR KO mice, lower open-field activity and deficits of motor learning on rotarod were reported (9). Other groups showed that stereotypic circular movements in Japanese waltzing mice were attenuated by ICV or intranasal application of SCT, which improved horizontal movements but did not influence the explorative behavior $(47,48)$. One recent study suggested SCT in enhancing eye-blink conditioning, a classical cerebellar-related learning behavior (49). In summary, past researches provided knowledge about SCT's neuropeptide function regarding motor behaviors. Nonetheless, systematic behavioral phenotyping was lacked, neither was the underlying mechanism.

Our research group for the first time developed a conditional SCT KO mouse model (Pur-SCT KO) in which Sct gene was specifically eliminated in cerebellar Purkinje neurons (20). We focused on Purkinje neurons because they regulated motor coordination and motor learning, as reported in Profilin $1 \mathrm{KO}(50)$ and $t b l$ mice (51). Motor behavioral genotyping in Pur-SCT KO mice showed significant impaired motor coordination and motor learning abilities (20): KO mice held a bar for a shorter time, spent longer climbing a wire mesh, and displayed insignificant improvements of rotarod latencies after repeated training. These abnormalities were replicated in SCT KO and SCTR KO mice (20), suggesting that Purkinje-derived SCT and SCT-SCTR axis were indispensable for motor behavioral controls.

This study supported the role of SCT in potentiating Purkinje neuron inhibitory transmission as previously reported (17). In this working model, SCT was endogenously produced from Purkinje neurons (52) following cytosolic calcium peak. It then functioned as a retrograde messenger, binding on presynaptic basket neurons, and induced inhibitory neurotransmitter GABA release (17). Other possible mechanisms still existed, however, as recent finding suggested that SCT suppressed intracellular trafficking of potassium channel Kv1.2 in both basket cell axonal terminals and Purkinje neuron dendrites (49). These reduced Kv1.2 ion currents led to presynaptic GABA release (53) and post-synaptic facilitation of parallel fiber-Purkinje neuron long-term depression (LTD) (54). Therefore, SCT worked via both pre- and post-synaptic pathways to modulate inhibitory transmission of Purkinje neurons (Figure 1E). In addition, SCT was also found in DCN (20), which were under inhibitory innervation of Purkinje neurons and sent output transmissions to premotor area in brain stem. Thus, SCT may mediate cerebellar transmission at multiple levels to accomplish motor behavioral control. Besides electrophysiological effects, SCT also affected cerebellar neurogenesis as that in hippocampal neurons. Supporting evidences included neural protection of cerebellar granular cell progenitors against ethanol toxicity (55) and behavioral phenotyping with later onset of cerebellarrelated neural reflexes in Pur-SCT KO juveniles (20). Further studies are required to describe in vivo neural developmental profiles under the application or deprivation of SCT.

\section{FUTURE PERSPECTIVES: THE FULL PARADIGM OF SCT IN NEUROBEHAVIORAL REGULATIONS}

Our current knowledge has established SCT as a pleiotropic neurohormone in behavioral modulations as summarized in Figure 1. These studies, however, are far from complete as SCT's entry routes to CNS, its functioning sites, and cellular mechanisms largely remained unknown. As mentioned above, peripheral SCT can directly stimulate CVO neurons without crossing the blood-brain 
barrier (BBB) or activating vagal afferent to inhibit food intake. On the other hand, the possibility of SCT to cross the BBB has also been reported (56) by transmembrane diffusion (57). In addition to peripheral sources, SCT is produced also from multiple central neurons, for example, in hypothalamus (12) and cerebellum (52). Within the CNS, SCT may reach its target sites by axonal transport. The multiple routes of SCT in affecting central functions are supported by the observation that either of ICV, IV, IP, or even intranasal administration of SCT (48) could induce behavioral changes.

Secretin's precise functioning sites and mechanisms can be investigated by more behavioral experiments, conditional $\mathrm{KO}$ animals, and in vivo neurophysiological studies. Firstly, the more robust and site-specific behavioral test can help to locate SCTmediated neurons. One example is eye-blink conditioning, which is closely related to LTD at parallel fiber-Purkinje cell synapse (58). Secondly, Sct or Sctr gene can be turned-off in a spatial- or temporal-specific manner by various Cre-Loxp models. As each behavior involves multiple neurons, cell-specific KO models can better elucidate sources and functional sites of SCT. Temporalspecific KO models, on the other hand, play an irreplaceable role in studying developmental effects of SCT. Lastly, we recommend the usage of in vivo electrophysiological and imaging techniques to study the real-time neural activity when animals are performing behavioral tasks. This should help us to establish more valid link between cellular pathways and behavioral phenotypes. By all these advanced methods, behavioral paradigms modulated by SCT could further be elaborated. These results can help us to better understand neurobehavioral modulations and to develop potential drug candidates against various behavioral disorders.

\section{ACKNOWLEDGMENTS}

This work was supported by HK government RGC Grant GRF 764510M, 765011M, 764812M, 765113M and CRF grant HKU6/CRF/11G to Billy K. C. Chow. Dr. L. T. O. Lee and Dr. R. Sekar also contributed to the revision of this manuscript.

\section{REFERENCES}

1. Bayliss WM, Starling EH. The mechanism of pancreatic secretion. J Physiol (1902) 28:325-53.

2. Mutt V, Carlquist M, Tatemoto K. Secretin-like bioactivity in extracts of porcine brain. Life Sci (1979) 25:1703-7. doi:10.1016/0024-3205(79)90472-7

3. Charlton CG, O'Donohue TL, Miller RL, Jacobowitz DM. Secretin immunoreactivity in rat and pig brain. Peptides (1981) 2(Suppl 1):45-9. doi:10.1016/01969781(81)90054-1

4. O'Donohue TL, Charlton CG, Miller RL, Boden G, Jacobowitz DM. Identification, characterization, and distribution of secretin immunoreactivity in rat and pig brain. Proc Natl Acad Sci USA (1981) 78:5221-4. doi:10.1073/pnas.78.8.5221

5. Siu FK, Sham MH, Chow BK. Secretin, a known gastrointestinal peptide, is widely expressed during mouse embryonic development. Gene Expr Patterns (2005) 5:445-51. doi:10.1016/j.modgep.2004.09.001

6. Siu FK, Sham MH, Chow BK. The prenatal expression of secretin receptor. Ann N Y Acad Sci (2006) 1070:561-5. doi:10.1196/annals.1317.081

7. Koves K, Kausz M, Reser D, Illyes G, Takacs J, Heinzlmann A, et al. Secretin and autism: a basic morphological study about the distribution of secretin in the nervous system. Regul Pept (2004) 123:209-16. doi:10.1016/j.regpep.2004.04.026

8. Yamagata T, Urano H, Weeber EJ, Nelson DL, Nishijima I. Impaired hippocampal synaptic function in secretin deficient mice. Neuroscience (2008) 154:1417-22. doi:10.1016/j.neuroscience.2008.04.037

9. Nishijima I, Yamagata T, Spencer CM, Weeber EJ, Alekseyenko O, Sweatt JD, et al. Secretin receptor-deficient mice exhibit impaired synaptic plasticity and social behavior. Hum Mol Genet (2006) 15:3241-50. doi:10.1093/hmg/ddl402
10. Toth ZE, Heinzlmann A, Hashimoto H, Koves K. Distribution of secretin receptors in the rat central nervous system: an in situ hybridization study. $J \mathrm{Mol}$ Neurosci (2013) 50:172-8. doi:10.1007/s12031-012-9895-1

11. Welch MG, Keune JD, Welch-Horan TB, Anwar N, Anwar M, Ludwig RJ, et al. Secretin: hypothalamic distribution and hypothesized neuroregulatory role in autism. Cell Mol Neurobiol (2004) 24:219-41. doi:10.1023/B:CEMN. 0000018618.59015.a2

12. Chu JY, Yung WH, Chow BK. Endogenous release of secretin from the hypothalamus. Ann N Y Acad Sci (2006) 1070:196-200. doi:10.1196/annals. 1317.012

13. Chu JY, Lee LT, Lai CH, Vaudry H, Chan YS, Yung WH, et al. Secretin as a neurohypophysial factor regulating body water homeostasis. Proc Natl Acad Sci U S A (2009) 106:15961-6. doi:10.1073/pnas.0903695106

14. Cheng CY, Chu JY, Chow BK. Central and peripheral administration of secretin inhibits food intake in mice through the activation of the melanocortin system. Neuropsychopharmacology (2011) 36:459-71. doi:10.1038/npp.2010.178

15. Lee VH, Lee LT, Chu JY, Lam IP, Siu FK, Vaudry H, et al. An indispensable role of secretin in mediating the osmoregulatory functions of angiotensin II. FASEB $J$ (2010) 24:5024-32. doi:10.1096/fj.10-165399

16. Lossi L, Bottarelli L, Candusso ME, Leiter AB, Rindi G, Merighi A. Transient expression of secretin in serotoninergic neurons of mouse brain during development. Eur J Neurosci (2004) 20:3259-69. doi:10.1111/j.1460-9568.2004.03816.x

17. Yung WH, Leung PS, Ng SS, Zhang J, Chan SC, Chow BK. Secretin facilitates GABA transmission in the cerebellum. J Neurosci (2001) 21:7063-8.

18. Koves K, Kausz M, Reser D, Horvath K. What may be the anatomical basis that secretin can improve the mental functions in autism? Regul Pept (2002) 109:167-72. doi:10.1016/S0167-0115(02)00200-8

19. Lee SM, Yung WH, Chen L, Chow BK. Expression and spatial distribution of secretin and secretin receptor in human cerebellum. Neuroreport (2005) 16:219-22. doi:10.1097/00001756-200502280-00003

20. Zhang L, Chung SK, Chow BK. The knockout of secretin in cerebellar Purkinje cells impairs mouse motor coordination and motor learning. Neuropsychopharmacology (2013) 39(6):1460-8. doi:10.1038/npp.2013.344

21. Morris RG, Anderson E, Lynch GS, Baudry M. Selective impairment of learning and blockade of long-term potentiation by an N-methyl-D-aspartate receptor antagonist, AP5. Nature (1986) 319:774-6. doi:10.1038/319774a0

22. Canales JJ. Comparative neuroscience of stimulant-induced memory dysfunction: role for neurogenesis in the adult hippocampus. Behav Pharmacol (2010) 21:379-93. doi:10.1097/FBP.0b013e32833e16b6

23. Samuels BA, Hen R. Neurogenesis and affective disorders. Eur J Neurosci (2011) 33:1152-9. doi:10.1111/j.1460-9568.2011.07614.x

24. Karelson E, Laasik J, Sillard R. Regulation of adenylate cyclase by galanin, neuropeptide $\mathrm{Y}$, secretin and vasoactive intestinal polypeptide in rat frontal cortex, hippocampus and hypothalamus. Neuropeptides (1995) 28:21-8. doi:10.1016/ 0143-4179(95)90070-5

25. Kuntz A, Clement HW, Lehnert W, Van Calker D, Hennighausen K, Gerlach M, et al. Effects of secretin on extracellular amino acid concentrations in rat hippocampus. J Neural Transm (2004) 111:931-9. doi:10.1007/s00702-0030082-y

26. Horvath K, Stefanatos G, Sokolski KN, Wachtel R, Nabors L, Tildon JT. Improved social and language skills after secretin administration in patients with autistic spectrum disorders. J Assoc Acad Minor Phys (1998) 9:9-15.

27. Sandler AD, Sutton KA, Deweese J, Girardi MA, Sheppard V, Bodfish JW. Lack of benefit of a single dose of synthetic human secretin in the treatment of autism and pervasive developmental disorder. N Engl J Med (1999) 341:1801-6. doi:10.1056/NEJM199912093412404

28. Owley T, Steele E, Corsello C, Risi S, Mckaig K, Lord C, et al. A double-blind, placebo-controlled trial of secretin for the treatment of autistic disorder. MedGenMed (1999) 3.

29. Dunn-Geier J, Ho HH, Auersperg E, Doyle D, Eaves L, Matsuba C, et al. Effect of secretin on children with autism: a randomized controlled trial. Dev Med Child Neurol (2000) 42:796-802. doi:10.1111/j.1469-8749.2000.tb00692.x

30. Coniglio SJ, Lewis JD, Lang C, Burns TG, Subhani-Siddique R, Weintraub A, et al. A randomized, double-blind, placebo-controlled trial of single-dose intravenous secretin as treatment for children with autism. J Pediatr (2001) 138:649-55. doi:10.1067/mpd.2001.112474

31. Krishnaswami S, Mcpheeters ML, Veenstra-Vanderweele J. A systematic review of secretin for children with autism spectrum disorders. Pediatrics (2011) 127:e1322-5. doi:10.1542/peds.2011-0428 
32. Jukkola PI, Rogers JT, Kaspar BK, Weeber EJ, Nishijima I. Secretin deficiency causes impairment in survival of neural progenitor cells in mice. Hum Mol Genet (2011) 20:1000-7. doi:10.1093/hmg/ddq545

33. Chu JY, Chung SC, Lam AK, Tam S, Chung SK, Chow BK. Phenotypes developed in secretin receptor-null mice indicated a role for secretin in regulating renal water reabsorption. Mol Cell Biol (2007) 27:2499-511. doi:10.1128/MCB. 01088-06

34. Lee LT, Ng SY, Chu JY, Sekar R, Harikumar KG, Miller LJ, et al. Transmembrane peptides as unique tools to demonstrate the in vivo action of a cross-class GPCR heterocomplex. FASEB J (2014). doi:10.1096/fj.13-246868

35. Chu JY, Cheng CY, Lee VH, Chan YS, Chow BK. Secretin and body fluid homeostasis. Kidney Int (2011) 79:280-7. doi:10.1038/ki.2010.397

36. Anil MH, Forbes JM. Effects of insulin and gastro-intestinal hormones on feeding and plasma insulin levels in sheep. Horm Metab Res (1980) 12:234-6. doi:10.1055/s-2007-996255

37. Grovum WL. Factors affecting the voluntary intake of food by sheep. 3 . The effect of intravenous infusions of gastrin, cholecystokinin and secretin on motility of the reticulo-rumen and intake. Br J Nutr (1981) 45:183-201. doi:10.1079/BJN19810091

38. Garlicki J, Konturek PK, Majka J, Kwiecien N, Konturek SJ. Cholecystokinin receptors and vagal nerves in control of food intake in rats. Am J Physiol (1990) 258:E40-5.

39. Chu JY, Cheng CY, Sekar R, Chow BK. Vagal afferent mediates the anorectic effect of peripheral secretin. PLoS One (2013) 8:e64859. doi:10.1371/journal. pone.0064859

40. Yang H, Wang L, Wu SV, Tay J, Goulet M, Boismenu R, et al. Peripheral secretininduced Fos expression in the rat brain is largely vagal dependent. Neuroscience (2004) 128:131-41. doi:10.1016/j.neuroscience.2004.06.027

41. Sobhani I, Bado A, Vissuzaine C, Buyse M, Kermorgant S, Laigneau JP, et al. Leptin secretion and leptin receptor in the human stomach. Gut (2000) 47:178-83. doi:10.1136/gut.47.2.178

42. Ambati S, Duan J, Choi YH, Hartzell DL, Della-Fera MA, Baile CA. ICV vs. VMH injection of leptin: comparative effects on hypothalamic gene expression. Behav Brain Res (2009) 196:279-85. doi:10.1016/j.bbr.2008.09.014

43. Li Y. Sensory signal transduction in the vagal primary afferent neurons. Curr Med Chem (2007) 14:2554-63. doi:10.2174/092986707782023334

44. Pulman KJ, Fry WM, Cottrell GT, Ferguson AV. The subfornical organ: a central target for circulating feeding signals. J Neurosci (2006) 26:2022-30. doi:10.1523/JNEUROSCI.3218-05.2006

45. Charlton CG, Miller RL, Crawley JN, Handelmann GE, O’Donohue TL. Secretin modulation of behavioral and physiological functions in the rat. Peptides (1983) 4:739-42. doi:10.1016/0196-9781(83)90029-3

46. Babarczy E, Szabo G, Telegdy G. Effects of secretin on acute and chronic effects of morphine. Pharmacol Biochem Behav (1995) 51:469-72. doi:10.1016/00913057(95)00009-L

47. Koves K, Kiss G, Heinzlmann A, Dochnal R, Manczinger M, Pal A, et al. Secretin attenuates the hereditary repetitive hyperactive movements in a mouse model. J Mol Neurosci (2011) 43:109-14. doi:10.1007/s12031-0109408-z

48. Heinzlmann A, Kiss G, Toth ZE, Dochnal R, Pal A, Sipos I, et al. Intranasal application of secretin, similarly to intracerebroventricular administration, influences the motor behavior of mice probably through specific receptors. J Mol Neurosci (2012) 48:558-64 doi:10.1007/s12031-012-9839-9

49. Williams MR, Fuchs JR, Green JT, Morielli AD. Cellular mechanisms and behavioral consequences of Kv1.2 regulation in the rat cerebellum. J Neurosci (2012) 32:9228-37. doi:10.1523/JNEUROSCI.6504-11.2012

50. Kullmann JA, Neumeyer A, Wickertsheim I, Bottcher RT, Costell M, Deitmer JW, et al. Purkinje cell loss and motor coordination defects in profilin1 mutant mice. Neuroscience (2012) 223:355-64. doi:10.1016/j.neuroscience. 2012.07.055

51. Porras-Garcia ME, Ruiz R, Perez-Villegas EM, Armengol JA. Motor learning of mice lacking cerebellar Purkinje cells. Front Neuroanat (2013) 7:4 doi:10.3389/fnana.2013.00004

52. Lee SM, Chen L, Chow BK, Yung WH. Endogenous release and multiple actions of secretin in the rat cerebellum. Neuroscience (2005) 134:377-86 doi:10.1016/j.neuroscience.2005.04.009

53. Southan AP, Robertson B. Modulation of inhibitory post-synaptic currents (IPSCs) in mouse cerebellar Purkinje and basket cells by snake and scorpion toxin K+ channel blockers. Br J Pharmacol (1998) 125:1375-81. doi:10.1038/sj. bjp.0702218

54. Lamont MG, Weber JT. The role of calcium in synaptic plasticity and motor learning in the cerebellar cortex. Neurosci Biobehav Rev (2012) 36:1153-62. doi:10.1016/j.neubiorev.2012.01.005

55. Hwang DW, Givens B, Nishijima I. Ethanol-induced developmental neurodegeneration in secretin receptor-deficient mice. Neuroreport (2009) 20:698-701. doi:10.1097/WNR.0b013e32832a5c9e

56. Banks WA, Goulet M, Rusche JR, Niehoff ML, Boismenu R. Differential transport of a secretin analog across the blood-brain and blood-cerebrospinal fluid barriers of the mouse. J Pharmacol Exp Ther (2002) 302:1062-9. doi:10.1124/ jpet.102.036129

57. Dogrukol-Ak D, Tore F, Tuncel N. Passage of VIP/PACAP/secretin family across the blood-brain barrier: therapeutic effects. Curr Pharm Des (2004) 10:1325-40. doi:10.2174/1381612043384934

58. Chen L, Bao S, Lockard JM, Kim JK, Thompson RF. Impaired classical eyeblink conditioning in cerebellar-lesioned and Purkinje cell degeneration (pcd) mutant mice. J Neurosci (1996) 16:2829-38.

Conflict of Interest Statement: The authors declare that the research was conducted in the absence of any commercial or financial relationships that could be construed as a potential conflict of interest.

Received: 03 April 2014; accepted: 08 May 2014; published online: 21 May 2014. Citation: Zhang L and Chow BKC (2014) The central mechanisms of secretin in regulating multiple behaviors. Front. Endocrinol. 5:77. doi: 10.3389/fendo.2014.00077 This article was submitted to Neuroendocrine Science, a section of the journal Frontiers in Endocrinology.

Copyright (C) 2014 Zhang and Chow. This is an open-access article distributed under the terms of the Creative Commons Attribution License (CC BY). The use, distribution or reproduction in other forums is permitted, provided the original author (s) or licensor are credited and that the original publication in this journal is cited, in accordance with accepted academic practice. No use, distribution or reproduction is permitted which does not comply with these terms. 